\title{
Association of Neutrophil-Lymphocyte Ratio and Platelet-Lymphocyte Ratio with Diabetic Kidney Disease among Adult Patients with Type 2 Diabetes Mellitus: A Meta-analysis of Observational Studies
}

\author{
Lilluck F. Alacapa, MD, Marc Gregory Y. Yu, MD and Mark Anthony S. Sandoval, MD \\ Section of Endocrinology, Diabetes and Metabolism, Department of Medicine, Philippine General Hospital, University of the Philippines Manila
}

\begin{abstract}
Objective. This meta-analysis aimed to evaluate the association of neutrophil-lymphocyte ratio (NLR) and plateletlymphocyte ratio (PLR) with the presence of diabetic kidney disease (DKD) among adult patients with Type 2 diabetes mellitus (T2DM).

Methods. A systematic search of articles was performed in various databases. Studies must have fulfilled the following criteria for inclusion: 1) Randomized controlled trial or observational study; 2) Included adults diagnosed with T2DM; 3) Reported data associating NLR or PLR with the presence of DKD; and 4) Controlled for confounders using logistic regression. Data analysis was performed using Review Manager 5.4 software. The estimates were derived using the generic inverse variance method and pooled using the random effects model. Results were presented as odds ratios (OR) and standard errors (SE) with 95\% confidence intervals (Cl), and graphically shown as forest plots. The $\mathrm{I}^{2}$ value and Chi-square test were used to assess heterogeneity across studies.
\end{abstract}

Results. Seven studies were included in the review, totaling 1,486 patients. All were cross-sectional studies and had satisfactory methodological quality as evaluated using the Newcastle-Ottawa Quality Assessment Scale. Pooled analysis from six studies showed a statistically significant association between increased NLR and the presence of DKD, defined as either the presence of albuminuria (95\% Cl, OR 1.68 [1.28, 2.19], p<0.01); or an estimated glomerular filtration rate (eGFR) $<60 \mathrm{~mL} / \mathrm{min} / 1.73 \mathrm{~m}^{2}(95 \% \mathrm{Cl}$, OR $1.56[1.09,2.23], p=0.01)$. In both analyses, there was no significant heterogeneity across studies $\left(\mathrm{I}^{2}=0 \%, \mathrm{Chi}^{2}=3.54\right.$; and $\mathrm{I}^{2}=28 \%$, $\mathrm{Chi}^{2}=2.76$ respectively). On the other hand, pooled analysis from two studies did not show a statistically significant association between PLR and albuminuria $(95 \% \mathrm{Cl}$, OR $1.75[0.85,3.60], \mathrm{p}=0.13)$, although both studies were homogeneous $\left(\mathrm{I}^{2}=0 \%, \mathrm{Chi}^{2}=0.57\right)$.

Conclusion. We found a statistically significant association between increased NLR and the presence of DKD. However, a similar association was not found with PLR. Larger studies with more robust designs are recommended.

Key Words: Type 2 diabetes, diabetic kidney disease, diabetic nephropathy, neutrophil-lymphocyte ratio, plateletlymphocyte ratio

Paper presented (Poster) in the 47 Annual Convention of the Philippine College of Physicians on May 7-10, 2017, at Manila, Philippines.

Paper presented (Oral) in the Seoul International Congress of Endocrinology and Metabolism on April 27-30, 2017, at Seoul, South Korea,

Paper presented (Poster) in the Philippine Society of Endocrinology, Diabetes and Metabolism Annual Convention on March 23-24, 2017, at Manila, Philippines.

Corresponding author: Marc Gregory Y. Yu, MD

Section of Endocrinology, Diabetes and Metabolism

Department of Medicine

Philippine General Hospital, University of the Philippines Manila

Taft Avenue, Manila 1000, Philippines

Email: marcgreggy@yahoo.com 


\section{INTRODUCTION}

The global epidemic of type 2 diabetes mellitus (T2DM) has led to the rising prevalence of diabetic kidney disease (DKD), one of its major microvascular complications. DKD occurs in $20-40 \%$ of all patients with diabetes and is the leading cause of end-stage renal disease (ESRD) worldwide, posing a huge economic burden on patients and their families. ${ }^{1,2}$ It begins with compensatory renal hypertrophy and hyperfiltration, followed by microalbuminuria with a urinary albumin excretion rate (UAER) of $30-300 \mathrm{mg} / 24$ hrs. or a spot urine albumin-creatinine ratio (UACR) of $30-300 \mathrm{mg} / \mathrm{g}$ creatinine $(\mathrm{Cr}) .^{3}$ Without timely intervention, patients can progress to macroalbuminuria (UAER $>300$ $\mathrm{mg} / 24 \mathrm{hrs}$. or UACR $>300 \mathrm{mg} / \mathrm{g} \mathrm{Cr}$ ), and eventually to clinically-evident DKD, with an estimated glomerular filtration rate $(\mathrm{eGFR})<60 \mathrm{~mL} / \mathrm{min} / 1.73 \mathrm{~m}^{2}$.

However, there are challenges to current diagnostic approaches for DKD. While histopathology remains the gold standard, concerns regarding cost and patient invasiveness preclude routine clinical use of kidney biopsies. ${ }^{4}$ A 24-hour urine collection for UAER measurement is also expensive, inconvenient, and technician-dependent. ${ }^{5}$ On the other hand, a simple dipstick urinalysis can be both cheap and easy to perform, but suffers from poor reliability and the inadvertent influence of several factors such as urinary tract infection, exercise, and stress. ${ }^{6}$

In recent years, there has been growing focus on the role of systemic inflammation in the development of microvascular complications in T2DM. Leukocyte infiltration has been observed in diabetes-induced renal injury, leading many investigators to consider the association of common hematologic indices with $\mathrm{DKD} .{ }^{7,8}$ In particular, the neutrophil-lymphocyte ratio (NLR) has been studied as a readily-available and potentially-affordable way of measuring inflammatory status in resource-limited settings, compared to other markers such as tumor necrosis factor, interleukins, and cytokines. In prospective studies following sepsis and major surgeries, NLR correlated with the severity of clinical course and critical illness. ${ }^{9}$ It has also been reported as a possible predictor of mortality in cardiovascular disease (CVD), having been associated with arterial stiffness, high coronary calcium scores, and ventricular arrhythmia risk. ${ }^{10}$

The platelet-lymphocyte ratio (PLR) has also been associated with several disease outcomes. While insufficient to establish a diagnosis of heart failure (HF), PLR values were higher in HF patients compared to age-sex matched controls. ${ }^{11}$ Similarly, median PLR values were higher in non-dipper hypertensive patients compared to dipper hypertensive patients, supporting the role of chronic inflammation in hypertensive pathophysiology. ${ }^{12}$ Given the increasing interest on the utility of these simple hematologic markers in clinical practice, the number of studies on NLR and PLR in DKD has also been steadily increasing, although the results have been generally inconsistent. We thus aimed to perform a meta-analysis to synthesize available data on the association of these hematologic parameters with DKD in adult patients with T2DM.

\section{METHODS}

\section{Search Strategy}

A systematic search for articles was performed by two independent authors (L.A. and M.G.Y.) in various databases such as MEDLINE, Embase, Scopus, Google Scholar, Herdin, and the Cochrane databases. For the hematologic markers of interest, the following search terms were used: "neutrophil-lymphocyte ratio", "neutrophil to lymphocyte ratio", "NLR", neutrophil", "platelet-lymphocyte ratio", "platelet to lymphocyte ratio", "PLR", platelet*. For the disease of interest, the following search terms were used: "diabetic nephropathy", "DN", "diabetic kidney disease", "DKD", "chronic kidney disease”, "CKD”, "chronic renal insufficiency", "renal complications", "albuminuria", "microalbuminuria", "macroalbuminuria", kidney*, renal", nephro*, nephriti", glomerulo*, "Type 2 diabetes mellitus", "T2DM", "diabetes mellitus", "DM", "non-insulin dependent diabetes mellitus", "NIDDM", "adult-onset diabetes mellitus". These terms were used both as text words and Medical Subject Headings $(\mathrm{MeSH})$. Conference proceedings and books of abstracts were also checked for possible articles. Searches were current as of June 2020.

\section{Study Selection}

Criteria for study inclusion were as follows: 1) The study must be a randomized controlled trial (RCT) or observational study; 2) The population must include adults diagnosed with T2DM according to standard criteria set by the American Diabetes Association; ${ }^{13}$ 3) The primary outcome measure must be the presence of DKD as defined by either albuminuria (UAER $\geq 30 \mathrm{mg} / 24 \mathrm{hr}$ or UACR $\geq 30$ $\mathrm{mg} / \mathrm{g} \mathrm{Cr}$ ), or eGFR $<60 \mathrm{~mL} / \mathrm{min} / 1.73 \mathrm{~m}^{2}$; 4) Must report data associating NLR or PLR with the presence of DKD; and 5) Should have controlled for confounders using logistic regression analysis. No restrictions on publication date, language, gender, or socio-ethnic group were made.

\section{Outcome Measures}

We defined NLR as the ratio of the absolute peripheral neutrophil count to the absolute peripheral lymphocyte count, while PLR was defined as the ratio of the absolute peripheral platelet count to the absolute peripheral lymphocyte count.

\section{Data Extraction and Management}

Two authors (L.A. and M.G.Y.) independently reviewed the studies for eligibility, with eligible studies subsequently undergoing methodology quality assessment using appropriate scales based on study type. A third author (M.A.S.) was invited to resolve any potential differences and disagreements. Studies that passed the screenings underwent 
data extraction. Data extracted from each study included author, year of publication, location of study, study design, sample size, type of population, and study outcomes.

\section{Statistical Analysis}

The study was analyzed using Review Manager version 5.4 software (The Cochrane Collaboration, London, $\mathrm{UK})$. Results were presented as odds ratios (OR) and standard errors (SE) with 95\% confidence intervals (CIs), and graphically shown as forest plots. The estimates were derived using the generic inverse variance method and pooled using the random effects model. Both ORs and SEs were first transformed into their natural logarithmic (In) values before data entry into the software. For studies that reported CIs but not SEs, In SEs were derived using the formula recommended by the Cochrane Collaboration: $\ln \mathrm{SE}=(\ln$ upper limit $\mathrm{CI}-\ln$ lower limit CI $) / 3.92,{ }^{14}$ The $\mathrm{I}^{2}$ and $\mathrm{Chi}^{2}$ tests were used to assess heterogeneity across studies, with significant heterogeneity defined as $\mathrm{I}^{2}>50 \%$ and $\mathrm{Chi}^{2}<0.10$, respectively.

\section{RESULTS}

\section{Search Results}

We retrieved 16 potentially relevant articles. Four articles were initially excluded because they studied different disease populations and/or dealt with different outcome measures. Of the remaining articles, five more were excluded due to lack of logistic regression analysis to control for confounders, leaving seven studies included. Figure 1 shows the flowchart for study selection, while Tables 1 and 2 summarize the list of included and excluded studies, respectively.

\section{Study Characteristics}

The seven included studies all had a cross-sectional design and were published from 2014-2019, totaling 1,486 patients. Interestingly, they originated from only three countries - China, Turkey, and Japan. Six studies evaluated the association of NLR with DKD: Of these, three defined DKD in terms of albuminuria alone; ${ }^{15,17,18}$ one defined DKD in terms of eGFR alone, ${ }^{19}$ and two investigated the asso-

Table 1. Characteristics of Included Articles

\begin{tabular}{|c|c|c|c|c|c|}
\hline $\begin{array}{l}\text { Study/ Year of } \\
\text { Publication }\end{array}$ & Country & Design & $\begin{array}{l}\text { Sample } \\
\text { size }\end{array}$ & Definition of DKD & $\begin{array}{l}\text { NLR and/or PLR value associated with DKD } \\
\text { (Mean +/- SD or Cl; Median) }\end{array}$ \\
\hline \multicolumn{6}{|l|}{ Studies on NLR and DKD } \\
\hline Huang $2014^{15}$ & China & Cross-sectional & 253 & UAER >30 mg/24 hrs & NLR $2.48 \pm 0.59$ \\
\hline Ciray $2014^{16}$ & Turkey & Cross-sectional & 114 & $\begin{array}{l}\text { UACR }>30 \mathrm{mg} / \mathrm{g} \mathrm{Cr} \text {; or } \\
\text { eGFR }<60 \mathrm{ml} / 1.73 \mathrm{~m}^{2}\end{array}$ & NLR $2.27 \pm 1.25$ \\
\hline Akbas $2014^{17}$ & Turkey & Cross-sectional & 200 & UACR >30 mg/g Cr & $\begin{array}{l}\text { UACR } 30-300 \text { mg/g Cr: NLR } 1.96 \text { (0.81-3.71) } \\
\text { UACR>300 mg/g Cr: NLR } 2.03 \text { (0.85-6.91) }\end{array}$ \\
\hline Tian $2017^{18}$ & China & Cross-sectional & 121 & UACR $>30 \mathrm{mg} / \mathrm{g} \mathrm{Cr}$ & NLR $2.14 \pm 1.06$ \\
\hline Zhang $2019^{19}$ & China & Cross-sectional & 247 & eGFR $<60 \mathrm{~mL} / 1.73 \mathrm{~m}^{2}$ & NLR 2.42 (median) \\
\hline Kawamoto $2019^{20}$ & Japan & Cross-sectional & 386 & $\begin{array}{l}\text { UACR }>30 \mathrm{mg} / \mathrm{g} \mathrm{Cr} \text {; or } \\
\text { eGFR }<60 \mathrm{~mL} / 1.73 \mathrm{~m}^{2}\end{array}$ & $\begin{array}{l}\text { eGFR } 45-60 \text { mL/1.73 m²: NLR } 1.99 \text { (1.42-2.75) } \\
\text { eGFR 30-45 mL/1.73 m²: NLR 2.21 (1.80-3.01) }\end{array}$ \\
\hline \multicolumn{6}{|l|}{ Studies on PLR and DKD } \\
\hline Akbas $2014^{17}$ & Turkey & Cross-sectional & 200 & UACR $>30 \mathrm{mg} / \mathrm{g} \mathrm{Cr}$ & $\begin{array}{l}\text { UACR } 30-300 \text { mg/g Cr: PLR } 115.22 \text { (50.51-276.04) } \\
\text { UACR>300 mg/g Cr: PLR } 118.45 \text { (57.73-361.33) }\end{array}$ \\
\hline Ren $2015^{21}$ & China & Cross-sectional & 330 & UAER > $30 \mathrm{mg} / 24 \mathrm{hrs}$ & PLR $105.38 \pm 41.37$ \\
\hline
\end{tabular}

$D K D$, diabetic kidney disease; NLR, neutrophil-lymphocyte ratio; PLR, platelet-lymphocyte ratio; SD, standard deviation; Cl, confidence interval; UAER, urinary albumin excretion rate; UACR, urine albumin-creatinine ratio; eGFR, estimated glomerular filtration rate

Table 2. List of Excluded Studies and Reasons for Exclusion

\begin{tabular}{|c|c|}
\hline Study & Reason for Exclusion \\
\hline $\begin{array}{l}\text { An } 2012^{22} \\
\text { Liu } 2016^{23}\end{array}$ & Different disease population \\
\hline $\begin{array}{l}\text { Lou } 2015^{24} \\
\text { Mineoka } 2015^{25}\end{array}$ & Different outcome measure \\
\hline $\begin{array}{l}\text { Kahraman } 2016^{26} \\
\text { Khandare } 2017^{27} \\
\text { Wheelock } 2018^{28} \\
\text { Mattared } 2019^{29} \\
\end{array}$ & $\begin{array}{l}\text { Performed linear regression only; did } \\
\text { not control for confounders using } \\
\text { logistic regression }\end{array}$ \\
\hline Demirtas $2015^{30}$ & $\begin{array}{l}\text { Logistic regression performed only with } \\
\text { HbA1c as outcome; not performed with } \\
\text { DKD as outcome }\end{array}$ \\
\hline
\end{tabular}

HbA1c, glycated hemoglobin; DKD, diabetic kidney disease

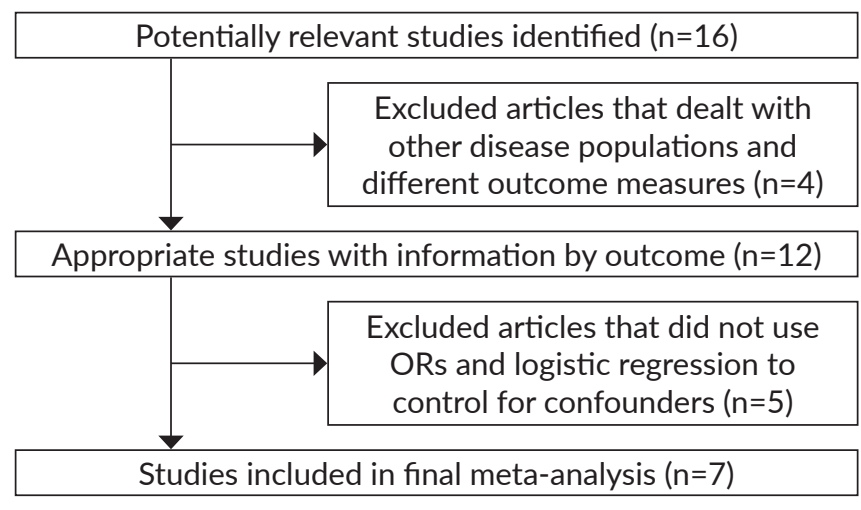

Figure 1. Flowchart of the Process of Study Retrieval. 
ciation of NLR with albuminuria and eGFR separately. ${ }^{16,20}$ The mean NLR associated with the presence of DKD ranged from 1.96 to 2.48 in these studies. ${ }^{15-20}$ For PLR, on the other hand, two studies looked at its association with albuminuria. The mean PLR associated with the presence of DKD ranged from 105.38 to 118.45 in both studies. ${ }^{17,21}$

Since all included studies were cross-sectional in design, they were evaluated for methodological quality using the Newcastle-Ottawa Quality Assessment Scale for Observational Studies, which assesses the risk of bias based on three main aspects: selection quality, comparability quality, and outcome quality. ${ }^{31}$ Except for lack of justification on sample size, the studies generally possessed satisfactory methodological quality, as outlined in Table 3.

\section{Data Synthesis}

\section{$N L R$ and DKD}

Six studies reported data on the association of NLR and DKD. ${ }^{15-20}$ We found a statistically significant association between increased NLR and DKD, be it in terms of albuminuria (95\% CI, OR 1.68 [1.28, 2.19], p $<0.01)^{15-18,20}$ or an eGFR $<60 \mathrm{~mL} / \mathrm{min} / 1.73 \mathrm{~m}^{2}(95 \% \mathrm{CI}$, OR $1.56[1.09,2.23], \mathrm{p}=0.01) .^{16,19,20}$ In both analyses, no significant heterogeneity was found across studies $\left(\mathrm{I}^{2}=0 \%\right.$, $\mathrm{Chi}^{2}=3.54$; and $\mathrm{I}^{2}=28 \%, \mathrm{Chi}^{2}=2.76$, respectively). Figure 2 shows the forest plot summarizing the association between NLR and albuminuria, while Figure 3 shows the forest plot summarizing the association between NLR and eGFR.

\section{PLR and DKD}

On the other hand, only two studies reported data on the association between PLR and DKD. ${ }^{17,21}$ No statistically significant association was found between PLR and albuminuria (95\% CI, OR $1.75[0.85,3.60], \mathrm{p}=0.13 ; \mathrm{I}^{2}=0 \%$, $\mathrm{Chi}^{2}=0.57$ ). Figure 4 shows the forest plot summarizing the association between PLR and DKD.

\section{DISCUSSION}

This meta-analysis summarized the available evidence on the association of NLR and PLR with the presence of DKD among adult patients with T2DM. We found a statistically significant association between increased NLR and DKD, but not between PLR and DKD. Epidemiological studies have shown that DKD is characterized by chronic inflammation and impaired endothelial function, causing relative neutrophilia and lymphocytopenia. This may help explain the significant association with increased NLR..$^{32}$ Moreover, our results are in agreement with the findings of increased NLR in non-diabetic patients with chronic kidney disease $(\mathrm{CKD}) .^{33}$

In contrast, we did not find a statistically significant association between PLR and DKD. This may have been due to several factors affecting platelet count. One such factor is antiplatelet use in T2DM, which has now been established in guidelines as part of standard of care for primary cardiovascular (CV) prevention in high-risk patients. ${ }^{34}$ The included studies did not explicitly mention whether

Table 3. Quality Assessment of Studies based on the Newcastle-Ottawa Scale for Observational Studies

\begin{tabular}{|c|c|c|c|c|c|c|c|}
\hline Study & $\begin{array}{l}\text { Huang } \\
2014\end{array}$ & $\begin{array}{l}\text { Ciray } \\
2014\end{array}$ & $\begin{array}{c}\text { Akbas } \\
2014\end{array}$ & $\begin{array}{l}\text { Ren } \\
2015\end{array}$ & $\begin{array}{l}\text { Tian } \\
2017\end{array}$ & $\begin{array}{c}\text { Zhang } \\
2019\end{array}$ & $\begin{array}{c}\text { Kawamoto } \\
2019\end{array}$ \\
\hline \multicolumn{8}{|l|}{ Selection Quality } \\
\hline Validated measurement tool to ascertain exposure & Yes & Yes & Yes & Yes & Yes & Yes & Yes \\
\hline Satisfactory response rate of respondents & Yes & Yes & Yes & Yes & Yes & Yes & Yes \\
\hline Sample size justified & No & No & No & No & No & No & No \\
\hline \multicolumn{8}{|l|}{ Comparability Quality } \\
\hline Subjects comparable & Yes & Yes & Yes & Yes & Yes & Yes & Yes \\
\hline Confounding factors controlled & Yes & Yes & Yes & Yes & Yes & Yes & Yes \\
\hline \multicolumn{8}{|l|}{ Outcome Quality } \\
\hline Independent outcome assessment & Yes & Yes & Yes & Yes & Yes & Yes & Yes \\
\hline Appropriate statistical tests used & Yes & Yes & Yes & Yes & Yes & Yes & Yes \\
\hline
\end{tabular}

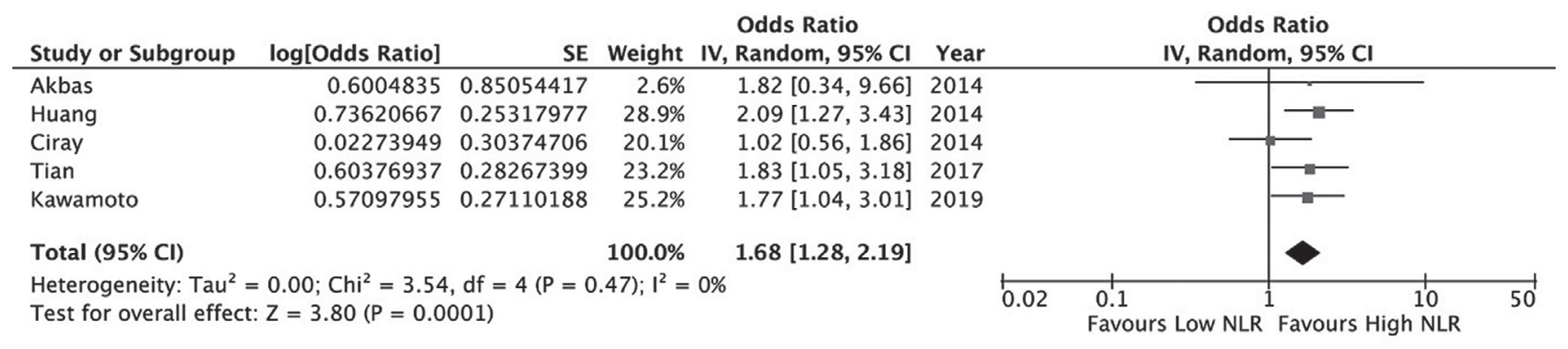

Figure 2. Forest plot showing the association of NLR with DKD (albuminuria). 


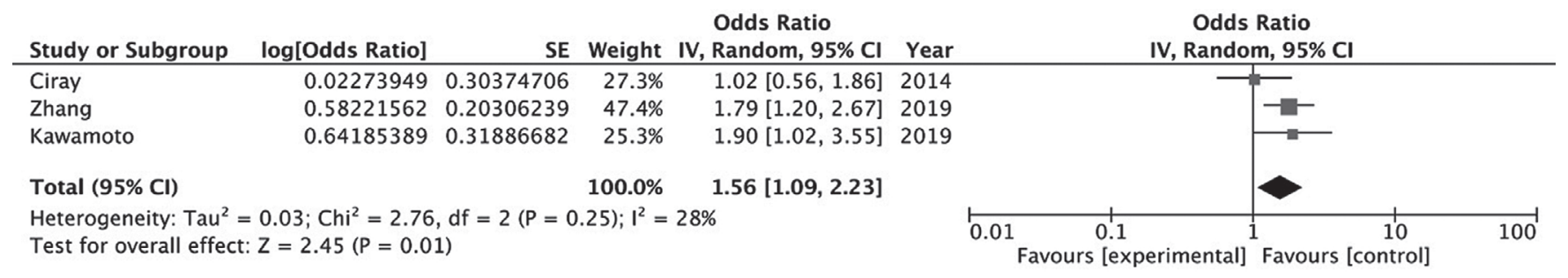

Figure 3. Forest plot showing the association of NLR with DKD (eGFR $<60 \mathrm{~mL} / \mathrm{min} / 1.73 \mathrm{~m}^{2}$ ).

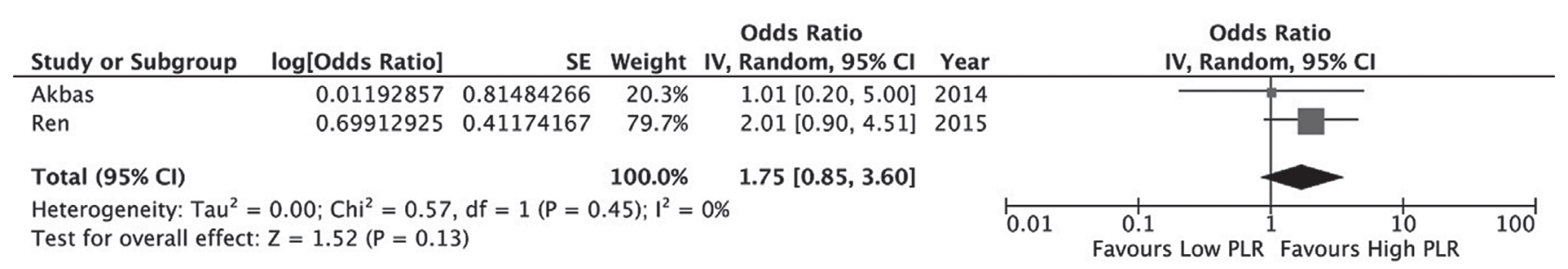

Figure 4. Forest plot showing the association of PLR with DKD (albuminuria).

antiplatelets, or any other drug that can affect platelet count for that matter, were given for any of the patients.

Since NLR and PLR are also affected by systemic conditions such as CVD, blood dyscrasias, infection, and malignancy, the presence of these comorbidities in T2DM patients may serve as possible confounders. This highlights the importance of careful patient selection, as well as performing a logistic regression analysis to control for the effect of confounders. While the studies by Huang and Kawamoto excluded pre-existing CVD during patient selection, ${ }^{15,20}$ the studies by Akbas, Ciray, Tian, and Zhang did not explicitly state whether cardiac patients were excluded. ${ }^{16-19}$ In addition, only the studies of Ciray, Huang, Zhang, and Kawamoto excluded the presence of concomitant malignancy and steroid use. ${ }^{15,16,19,20}$ All studies, however, were able to exclude ongoing infection and perform logistic regression analysis with regards to other variables such as age, smoking status, glycemic control, blood pressure, and serum creatinine and lipid levels, among others.

Our findings are consistent with the results of an earlier meta-analysis, which found a similar significant association between NLR and DKD. ${ }^{35}$ The same paper further indicated that NLR values were likewise higher among patients with diabetic retinopathy (DR). While the authors did not evaluate PLR, they observed that mean platelet volume and platelet distribution width were also significantly higher among patients with DR or DKD. Our paper, however, differs from this earlier meta-analysis in that we deliberately excluded studies with insufficient methodological quality by failing to control for confounders. ${ }^{26,30}$

The strength of our paper lies in its applicability to Asian patients, as the included studies were all from Asian countries (Turkey, Japan, and China). Asian patients with T2DM have been consistently shown to possess higher rates of $\mathrm{DKD}$, compared to their Caucasian counterparts.
This is compounded by the fact that many Asian countries are developing nations that are facing resource constraints, highlighting the need for cheap, convenient, and reliable diagnostic tests. ${ }^{36}$

Our study's limitations include the relatively small sample sizes and the cross-sectional designs of the included articles. Therefore, we cannot draw substantial prognostic or predictive relationships from our results. Due to the inherently heterogenous nature of observational studies, we chose to use the random effects model in our analysis irrespective of the $\mathrm{I}^{2}$ and $\mathrm{Chi}^{2}$ test results for heterogeneity. Furthermore, the small number of studies precluded the performance of a funnel plot to investigate for possible publication bias, as it is not recommended for the analyses of outcomes containing less than ten studies. ${ }^{37}$ Last but most importantly, there is a lack of agreement among the different studies regarding the optimal cutoff to define increased NLR and PLR, which may affect the future applicability of their use as potential markers for DKD.

\section{CONCLUSION}

We found a statistically significant association between increased NLR and the presence of DKD, but not with PLR. While there exists a potential for the applicability of these hematologic indices in clinical practice, it is still not yet known as to what stage of DKD they would prove useful. Hence, it is too early to recommend routine use of these indices for the diagnosis of DKD in guidelines. Larger studies with more robust designs are recommended.

\section{Statement of Authorship}

All authors participated in data collection and analysis, and have approved the final version submitted. 


\section{Author Disclosure}

All authors declared no conflicts of interest.

\section{Funding Source}

The authors have no external funding source.

\section{REFERENCES}

1. Molitch ME, De Fronzo RA, Franz MJ. Nephropathy in diabetes. Diabetes Care. 2004; 27(1):s79-s83.

2. Gheith O, Farouk N, Nampoory N, Halim MA, Al-Otaibi T. Diabetic kidney disease: Worldwide difference of prevalence and risk factors. J Nephropharmacol. 2016; 5(1):49-56.

3. Yu MG, Blanquisco L, Anonuevo-Cruz MC. Efficacy of heparinoid supplementation on mortality and disease progression in adults with diabetic kidney disease. J ASEAN Fed Endocr Soc. 2017; 32(1):20-6.

4. Gluck C, Ko YA, Susztak K. Precision medicine approaches to diabetic kidney disease: Tissue as an issue. Curr Diab Rep. 2017 May; 17(5):30.

5. Narva AS, Bilous RW. Laboratory assessment of diabetic kidney disease. Diabetes Spectr. 2015 Aug; 28(3):162-6.

6. Nagrebetsky A, Jin J, Stevens R, James T, Adler A, Park P, et al. Diagnostic accuracy of urine dipstick testing in screening for microalbuminuria in type 2 diabetes: A cohort study in primary care. Fam Pract. 2013 Apr;30(2):142-52.

7. Galkina E, Ley K. Leukocyte recruitment and vascular injury in diabetic nephropathy. J Am Soc Nephrol. 2006; 17(2):1710-7.

8. Xiao X, Ma B, Dong B, Zhao P, Tai N, Chen E, et al. Cellular and humoral immune responses in the early stages of diabetic nephropathy in NOD mice. J Autoimmun. 2009; 32(2):85-93.

9. Zahorec R. Ratio of neutrophil to lymphocyte counts- rapid and simple parameter of systemic inflammation and stress in critically ill. Bratislavske Lekarske Listy 2001; 102:5-14.

10. Bhat T, Teli S, Rijal J, Bhat, Raza M, Khoueiry G, et al. Neutrophilto-lymphocyte ratio and cardiovascular diseases: a review. Expert Rev. Cardiovasc Ther. 2013; 11(1):55-9.

11. Durmus E, Kivrak T, Gerin F, Sunbul M, Sari I, Erdogan O. Neutrophil-to-lymphocyte ratio and platelet-to-lymphocyte ratio are predictors of heart failure. Arq Bras Cardiol. 2015; 105(6):606-13.

12. Bayrakci N, Ozkayar N, Akyel F, Ates I, Akyel S, Dede F. The plateletto-lymphocyte ratio as an inflammatory marker in non-dipper hypertensive patients. Hippokratia. 2015; 19(2):114-8.

13. American Diabetes Association. Classification and Diagnosis of Diabetes: Standards of Medical Care in Diabetes-2020. Diabetes Care. 2020 Jan; 43 (Supplement 1):S14-S31.

14. The Cochrane Collaboration. Obtaining standard errors from confidence intervals and P-values: ratio measures [Internet]. [cited 2020 June 12]. Available from: https://handbook-5-1.cochrane.org/ chapter_7/7_7_7_3_obtaining_standard_errors_from_confidence_ intervals_and.htm

15. Huang W, Huang J, Liu Q, Lin F, He Z, Zeng Z, et al. Neutrophillymphocyte ratio is a reliable predictive marker for early-stage diabetic nephropathy. Clinical Endocrinology. 2015; 82:229-33.

16. Ciray H, Aksoy AH, Ulu N, Cizmecioglu A, Gaipov A, Solak Y. Nephropathy, but not angiographically-proven retinopathy, is associated with neutrophil-to- lymphocyte ratio in patients with type 2 diabetes. Exp Clin Endocr Diab. 2015; 123:267-71.

17. Akbas EM, Demirtas L, Ozcicek A, Timuroglu A, Bakirci EM, Hamur H, et al. Association of epicardial adipose tissue, neutrophilto-lymphocyte ratio and platelet-to-lymphocyte ratio with diabetic nephropathy. Int J Clin Exp Med. 2014; 7(7):1794-801.

18. Tian MY, Lu Q, Yin ZF, Li T, Gu YH, Wang R, et al. Relationship between neutrophil-to-lymphocyte ratio and urine-to-creatinine ratio in patients with type 2 diabetes mellitus. J Postgrad Med. 2017; 30(10):1061-4.

19. Zhang JL, Zhang R, Wang YT, Wu YC, Li HY, Han QQ, et al. Effects of neutrophil-lymphocyte ratio on renal function and histologic lesions in patients with diabetic nephropathy. Nephrology (Carlton). 2019; 24(11):1115-21.

20. Kawamoto R, Ninomiya D, Kikuchi A, Akase T, Kasai Y, Kusunoki $\mathrm{T}$, et al. Association of neutrophil-to-lymphocyte ratio with early renal dysfunction and albuminuria among diabetic patients. Int Urol Nephrol. 2019; 51(3):483-90.

21. Ren HX, Wu X, Zhao W, Zhang XH, Zhu SQ, Zhang H. Relationship between peripheral blood platelet-to-lymphocyte ratio and type 2 diabetic nephropathy. China J Endocrinol Metab. 2015; 31(5):406-7.

22. An X, Mao HP, Wei X, Chen JH, Yang X, Li ZB, et al. Elevated neutrophil-to-lymphocyte ratio predicts overall and cardiovascular mortality in maintenance peritoneal dialysis patients. Int Urol Nephrol. 2012; 44(5):1521-8.

23. Liu X, Huang R, Wu H,Wu J, Wang J, Yu X, et al. Patient characteristics and risk factors of early and late death in incident peritoneal dialysis patients. Sci Rep. 2016; 6:32359.

24. Lou MQ, Luo P, Tang R, Peng YX, Yu SY, Huang WJ, et al. Relationship between neutrophil-lymphocyte ratio and insulin resistance in newly diagnosed type 2 diabetes mellitus patients. BMC Endocrine Disorders. 2015; 15:9.

25. Mineoka $Y$, Ishii $M$, Hashimoto $Y$, Nakamura N, Katsumi $Y$, Isono M, et al. Neutrophil-lymphocyte ratio correlates with limited joint mobility of hand in patients with type 2 diabetes. Endocr J. 2018; 65(10):1011-7.

26. Kahraman C, Kahraman NK, Aras B, Cosgun S, Gulcan E. The relationship between neutrophil-to-lymphocyte ratio and albuminuria in type 2 diabetic patients: A pilot study. Arch Med Sci. 2016; 12(3):571-5.

27. Khandare SA, Chittawar S, Nahar N, Dubey TN, Qureshi Z. Study of neutrophil-lymphocyte ratio as novel marker for diabetic nephropathy in type 2 diabetes. Indian J Endocrinol Metab. 2017; 21(3): 387-92.

28. Wheelock KM, Saulnier PJ, Tanamas SK, Vijayakumar P, Weil EJ, Looker HC, et al. White blood cell fractions correlate with lesions of diabetic kidney disease and predict loss of kidney function in type 2 diabetes. Nephrol Dial Transplant. 2018; 33(6):1001-9.

29. Mattared AM, Esheba NE, Elshora OA, Mohamed WS. Mean platelet volume and neutrophil to lymphocyte ratio in prediction of early diabetic nephropathy in type 2 diabetics. Diabetes Metab Syndr. 2019; 13(2):1469-73.

30. Demirtas L, Degirmenci H, Akbas EM, Ozcicek A,Timuroglu A, Gurel A, et al. Association of hematological indicies with diabetes, impaired glucose regulation and microvascular complications of diabetes. Int J Clin Exp Med. 2015; 8(7):11420-7.

31. Wells GA, Shea B, O'Connell D, Peterson J, Welch V, Losos M, et al. The Newcastle-Ottawa Scale (NOS) for assessing the quality of nonrandomized studies in meta-analyses [Internet]. [cited 2020 June 12]. Available from: http://wwwohrica/programs/clinical_ epidemiology/oxfordasp

32. Pitsavos C, Tampourlou M, Panagiotakos DB, Skoumas Y, Chrysohoou C, Nomikos T, et al, Association between low-grade systemic inflammation and type 2 diabetes mellitus among men and women from the ATTICA study. Rev Diabet Stud. 2007; 4:98-104.

33. Binnetoglu E, Sengul E, Halhalli G, Dindar S, Sen H. Is neutrophillymphocyte ratio an indicator for proteinuria in chronic kidney disease. J Clin Lab Analysis. 2014; 28:487-92.

34. American Diabetes Association. Cardiovascular Disease and Risk Management: Standards of Medical Care in Diabetes-2020. Diabetes Care. 2020 Jan; 43 (Supplement 1):S111-S134.

35. Liu JX, Liu XG, Li YP, Quan JX, Wei SH, An SQ, et al. The association of neutrophil-to-lymphocyte ratio, mean platelet volume, and platelet distribution width with diabetic retinopathy and nephropathy: A meta-analysis. Biosci Rep 2018; 38(3):BSR20180172.

36. Wu AYT, Kong NCT, de Leon FA, Pan CY, Tai TY, Yeung VTF, et al. An alarmingly high prevalence of diabetic nephropathy in Asian Type 2 diabetic patients: the MicroAlbuminuria Prevalence (MAP) Study. Diabetologia. 2005; 48:17-26.

37. Simmonds, M. Quantifying the risk of error when interpreting funnel plots. Syst Rev. 2015; 11(4):24. 